\section{Reproductive Characteristics for Self-compatibility and Seedlessness in 'Nishiuchi Konatsu', a Bud Mutation of Hyuganatsu (Citrus tamurana hort. ex Tanaka)}

\author{
Chitose Honsho', Masami Kotsubo, Yuri Fukuda, and Yosui Hamabata \\ Faculty of Agriculture, University of Miyazaki, 1-1 Gakuenkibanadai-nishi, \\ Miyazaki 889-2192, Japan \\ Yoshikazu Kurogi and Aya Nishiwaki \\ Field Science Center, Faculty of Agriculture, University of Miyazaki, 1-1 \\ Gakuenkibanadai-nishi, Miyazaki 889-2192, Japan
}

Takuya Tetsumura

Faculty of Agriculture, University of Miyazaki, 1-1 Gakuenkibanadai-nishi, Miyazaki 889-2192, Japan

\begin{abstract}
Additional index words. citrus, Hyuganatsu, pollination, seed abortion, seed type, selfincompatibility
\end{abstract}

\begin{abstract}
The reproductive characteristics of 'Nishiuchi Konatsu', a bud mutation of Hyuganatsu that is self-incompatible, were examined. A pollination experiment resulted in Hyuganatsu $\times$ 'Nishiuchi Konatsu' and 'Nishiuchi Konatsu' self-pollination produced their fruit, whereas 'Nishiuchi Konatsu' $\times$ Hyuganatsu cannot produce fruit as a result of early dropping of premature fruits within the first 10 weeks after pollination. Considering the self-incompatible nature of Hyuganatsu, this result implies a mutation of the pollen-expressed gene(s) associated with the self-incompatibility occurring in 'Nishiuchi Konatsu'. When 'Nishiuchi Konatsu' pollen was used for several citrus accessions (Hyuganatsu, 'Nishiuchi Konatsu', Hassaku, and 'Sweet Spring'), it was observed that the number of normal seeds decreased and that of aborted seeds increased. Interestingly, the extent of seed abortion differed among seed parents. Hyuganatsu and 'Nishiuchi Konatsu' lost most of their normal seeds. In contrast, Hassaku lost relatively lesser seeds, and 'Sweet Spring' lost only a few seeds. Moreover, Hassaku fruits obtained by pollination with 'Nishiuchi Konatsu' pollen showed various proportions of normal and aborted seeds even among individual fruits. 'Nishiuchi Konatsu' pollen did not affect the fruit characteristics, with some exceptions in Hyuganatsu, 'Nishiuchi Konatsu', and Hassaku. All the characteristics were superior in Hyuganatsu-pollinated fruits compared with 'Nishiuchi Konatsu'-pollinated ones in 'Sweet Spring'. In conclusion, it was demonstrated that 'Nishiuchi Konatsu' has two agriculturally important traits: self-compatibility and seed abortion. It can be useful for elucidating the mechanisms and as the genetic resources that introduce these traits.
\end{abstract}

Hyuganatsu (Citrus tamurana hort. ex Tanaka), which happened to be found as a chance seedling in Miyazaki Prefecture

\footnotetext{
Received for publication 26 May 2009. Accepted for publication 21 July 2009 .

This work was supported, in part, by Grants in Aid for Young Scientists (B) (19780021 and 21780024) given to C.H. from the Ministry of Education, Culture, Sports, Science and Technology (MEXT), and the Japan Society for the Promotion of Science (JSPS).

We are grateful to Mitsutoshi Tanaka at the Kochi Agricultural Research Center for providing us with 'Nishiuchi Konatsu' pollen. We also thank Makoto Nakamura for allowing us to use 'Nishiuchi Konatsu' trees for our pollination experiments.

${ }^{1}$ To whom reprint requests should be addressed; e-mail chitose@cc.miyazaki-u.ac.jp.
}

$\approx 150$ years ago, is a late-season citrus plant. It is unique to prepare eating this fruit for eating; with a knife, the fruit is peeled off only the flavedo and the segment and albedo are tasted together. Hyuganatsu is now produced as a special product in Miyazaki, Kochi Prefecture, and elsewhere. Hyuganatsu is substantially self-incompatible without parthenocarpic traits (Miwa, 1951). As a result of these characteristics, a pollenizer is required to set the fruits, which ultimately contain many seeds (Yamamoto et al., 1995). However, in citriculture, seedlessness is one of the most important factors in determining the commercial value of a fruit. Gibberellic acid during the early stages of fruit development (Yamamoto and Iwasaki, 1994) and pollination with pollens from $4 \times$ citrus trees (Imai et al., 2007; Yamashita, 1976; Yamashita et al., 1990) have been successfully used to reduce the number of seeds in the fruit. Although some Hyuganatsu growers have adopted these techniques, it is desirable to develop a seedless cultivar for reducing costs and labor.

A bud mutation of Hyuganatsu, known as 'Nishiuchi Konatsu', was found $\approx 25$ years ago in Kochi Prefecture. 'Nishiuchi Konatsu' bears fruit in an orchard of monoculture and produces almost no seeds inside the fruit; thus, it is regarded as a favorable cultivar for introduction into Miyazaki Prefecture. Kitajima et al. (2001) researched both pollen tube growth and seed development of 'Nishiuchi Konatsu', which was mainly used as a seed parent. Tanioka et al. (2001) found an interesting phenomenon; a common variety of Hyuganatsu showed a decrease in the number of seeds when pollinated with 'Nishiuchi Konatsu' pollen. However, little basic information is available on the reproductive characteristics of 'Nishiuchi Konatsu', especially as a pollenizer. In this study, to elucidate the reproductive characteristics of 'Nishiuchi Konatsu', especially its pollen, a pollination experiment was conducted using the commonly found variety of Hyuganatsu, Hassaku (Citrus hassaku hort. ex Tanaka), 'Sweet Spring', which is a hybrid between Satsuma mandarin (Citrus unshiu Marc. cv. Ueda unshu) and Hassaku, and 'Nishiuchi Konatsu' and traced their fruit setting and fruit development. Finally, the characteristics of the harvested fruits were investigated.

\section{Materials and Methods}

Plant materials. The following plant materials were used: the commonly found variety of Hyuganatsu (hereafter, Hyuganatsu); its bud-mutated cultivar Nishiuchi Konatsu; Hassaku cv. Nomabeni Hassaku, which is a bud sport of a commonly used type of Hassaku (hereafter, Hassaku); and 'Sweet Spring'. All accessions used in this study produced monoembryonic seeds. Hyuganatsu, Hassaku, and 'Sweet Spring' were grown at the Field Science Center, University of Miyazaki, and 'Nishiuchi Konatsu' was grown in a commercial orchard in Kiyotake Town, Miyazaki Prefecture. All trees in each strain were clones with identical genetic background.

The flowers of each accession at the balloon stage were collected from the previously mentioned fields, except for 'Nishiuchi Konatsu' because it bloomed at the beginning to middle of May, a little bit later than others that bloomed at the end of April to the beginning of May. Thus, the flowers of 'Nishiuchi Konatsu', which were grown in a greenhouse, were supplied from the Fruit Tree Station at the Kochi Agricultural Research Center. Anthers were excised from the flowers and dehisced by overnight incubation at $30{ }^{\circ} \mathrm{C}$. They were then sieved with a tea strainer to recover pollen grains, which were maintained at $4{ }^{\circ} \mathrm{C}$ in a refrigerator until pollination time.

Pollination experiment. A pollination experiment was conducted with nine combinations. 
The pollination combinations and the numbers of flowers pollinated are summarized in Table 1. The numbers of trees used as seed parent were three, three, two, and three for Hyuganatsu, 'Nishiuchi Konatsu', Hassaku, and 'Sweet Spring', respectively. For each seed parent, the numbers of flowers used for each combination were equalized within accessions. All the pollination processes were performed in May 2007. However, an additional pollination was performed in 2008 only for Hyuganatsu $\times$ Hassaku, because the number of fruits harvested in 2007 was not enough for the analysis. Inflorescences with leaves were selected for pollination; excess flowers and leafless inflorescences were removed so that one flower remained in a bearing shoot. Flowers at the balloon stage were emasculated with forceps and pollinated by a brush. Pollinated flowers were immediately paper-bagged to avoid pollination with unknown pollen.

Measurement of fruit development and characteristics. After pollination, fruit sets were recorded for each combination every 2 weeks until harvest. Using a digital caliper, the longitudinal and horizontal diameters for the selected fruits in each combination were measured every 2 weeks until harvest. For each combination, the number of fruits chosen for size measurement is listed in Table 1. Measurements of longitudinal and horizontal diameters started 2 weeks and 4 weeks after pollination, respectively.

All the harvested fruits were used to measure fruit weight, longitudinal and horizontal diameters, total soluble solids (TSS), titratable acidity (TA), and number of seeds. The TSS value was measured using a hand refractometer and indicated as a Brix value; the TA, which was determined by titration of 1 $\mathrm{mL}$ juice with $0.1 \mathrm{M} \mathrm{NaOH}$, was represented as citric acid content in $100 \mathrm{~mL}$ of juice. Seeds obtained from the fruits were categorized as normal, aborted, or undeveloped. Thin and nonfulfilled seeds were regarded as aborted and nondeveloped seeds, respectively. Aborted seeds and nondeveloped seeds were ordered by size; seeds with sizes of $5 \mathrm{~mm}$ or greater were considered aborted and those with sizes less than $5 \mathrm{~mm}$ were considered nondeveloped. All the data were subjected to a $t$ test to reveal the statistical differences between pollen sources at the 5\% level. Nondeveloped seeds were omitted from the analysis. A homogeneity test was performed for the number of normal and aborted seeds of Hassaku fruits with each pollen source by a $\chi^{2}$ test. The $\chi^{2}$ test was also applied to find the best-matching segregating ratio with the expected ratios of $2: 1,1: 1$, and $1: 2$, in which Mendelian segregation ratio was presumed.

\section{Results}

Hyuganatsu can set fruit by pollination with both Hassaku and 'Nishiuchi Konatsu' pollens (data not shown). When 'Nishiuchi Konatsu' was the seed parent, pollination using Hassaku and self-pollen successfully resulted in fruit setting, whereas fruits pollinated with Hyuganatsu had dropped com- pletely within 10 weeks without any mature fruits being harvested (Fig. 1). When Hassaku and 'Sweet Spring' were used as seed parents, although physiological drop was observed, fruits were set by whatever pollen was used in this study (data not shown).

There was no significant difference in fruit growth among pollen sources at each measurement date for Hyuganatsu, Hassaku (data not shown), and 'Nishiuchi Konatsu' (Fig. 2). 'Nishiuchi Konatsu' fruits pollinated with Hyuganatsu pollen showed apparently inferior growth compared with the other fruits. It was shown that the 'Sweet Spring' fruits pollinated with Hyuganatsu pollen had significantly superior growth compared with fruits obtained from 'Nishiuchi Konatsu' pollen (Fig. 2). The first statistical significances of the longitudinal and horizontal diameters appeared at 8 and 6 weeks after pollination, respectively.

Most fruit weights, longitudinal and horizontal diameters, TSS, and TA in the Hyuganatsu, 'Nishiuchi Konatsu', and Hassaku were not significantly different among pollen sources (Table 2). Only the TA in Hyuganatsu and the TSS content in 'Nishiuchi Konatsu' were affected by the pollen source. 'Sweet Spring' fruits obtained by pollination with Hyuganatsu pollen were superior in all traits compared with fruits obtained by pollination with 'Nishiuchi Konatsu' pollen.

Seed weight was considerably influenced by pollen source (Table 2). It was demonstrated that the total seed weight of the fruits grown by 'Nishiuchi Konatsu' pollination significantly decreased for all seed parents. The numbers of seeds obtained for Hyuganatsu and 'Nishiuchi Konatsu' clearly showed the effect of the pollen source (Fig. 3). When 'Nishiuchi Konatsu' pollen was used, normal seeds were almost completely missing, whereas many aborted seeds were observed. In contrast, most of seeds in the fruits were normal when Hassaku pollen was used. When Hassaku and 'Sweet Spring' were used as seed parents, the use of 'Nishiuchi Konatsu' pollen significantly decreased the number of normal seeds but increased aborted seeds. However, some normal seeds were still produced in Hassaku (Fig. 4) and 'Sweet Spring'. In contrast, normal seeds almost completely vanished in Hyuganatsu fruits pollinated with 'Nishiuchi Konatsu' pollen. Interestingly, the number of normal and aborted seeds in Hassaku $\times$ 'Nishiuchi Konatsu' fruits varied extensively among individual fruits. The $\chi^{2}$ homogeneity test resulted in the fact that the fruits pollinated with Hyuganatsu pollen were homogeneous,

Table 1. Pollination combinations, number of pollinated flowers, and number of fruits used for size measurements in 2007.

\begin{tabular}{llcc}
\hline Seed parent & \multicolumn{1}{c}{ Pollen source } & $\begin{array}{c}\text { No. of pollinated } \\
\text { flowers }\end{array}$ & $\begin{array}{c}\text { No. of fruits } \\
\text { measured for size }\end{array}$ \\
\hline Hyuganatsu & 'Nishiuchi Konatsu' & 60 & 25 \\
'Nishiuchi Konatsu' & 'Nassaku & 60 & 10 \\
& 'Hassakuchi Konatsu' & 60 & 15 \\
Hassaku & Hyuganatsu & 60 & 15 \\
& 'Nishiuchi Konatsu' & 60 & 15 \\
'Sweet Spring' & Hyuganatsu & 60 & 15 \\
& 'Nishiuchi Konatsu' & 60 & 15 \\
& Hyuganatsu & 30 & 15 \\
\hline
\end{tabular}

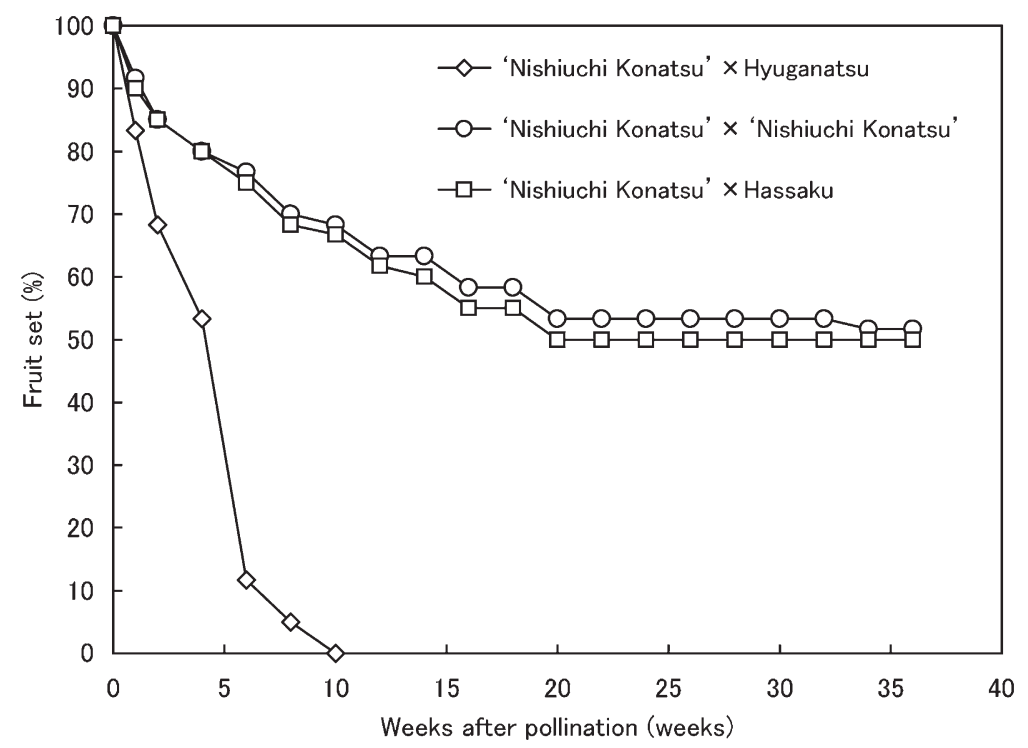

Fig. 1. Time-course changes of fruit set in 'Nishiuchi Konatsu' fruit pollinated with different pollens. Symbols indicate pollen sources: Hyuganatsu $(\diamond)$, 'Nishiuchi Konatsu' $(\bigcirc)$, and Hassaku $(\square)$. 

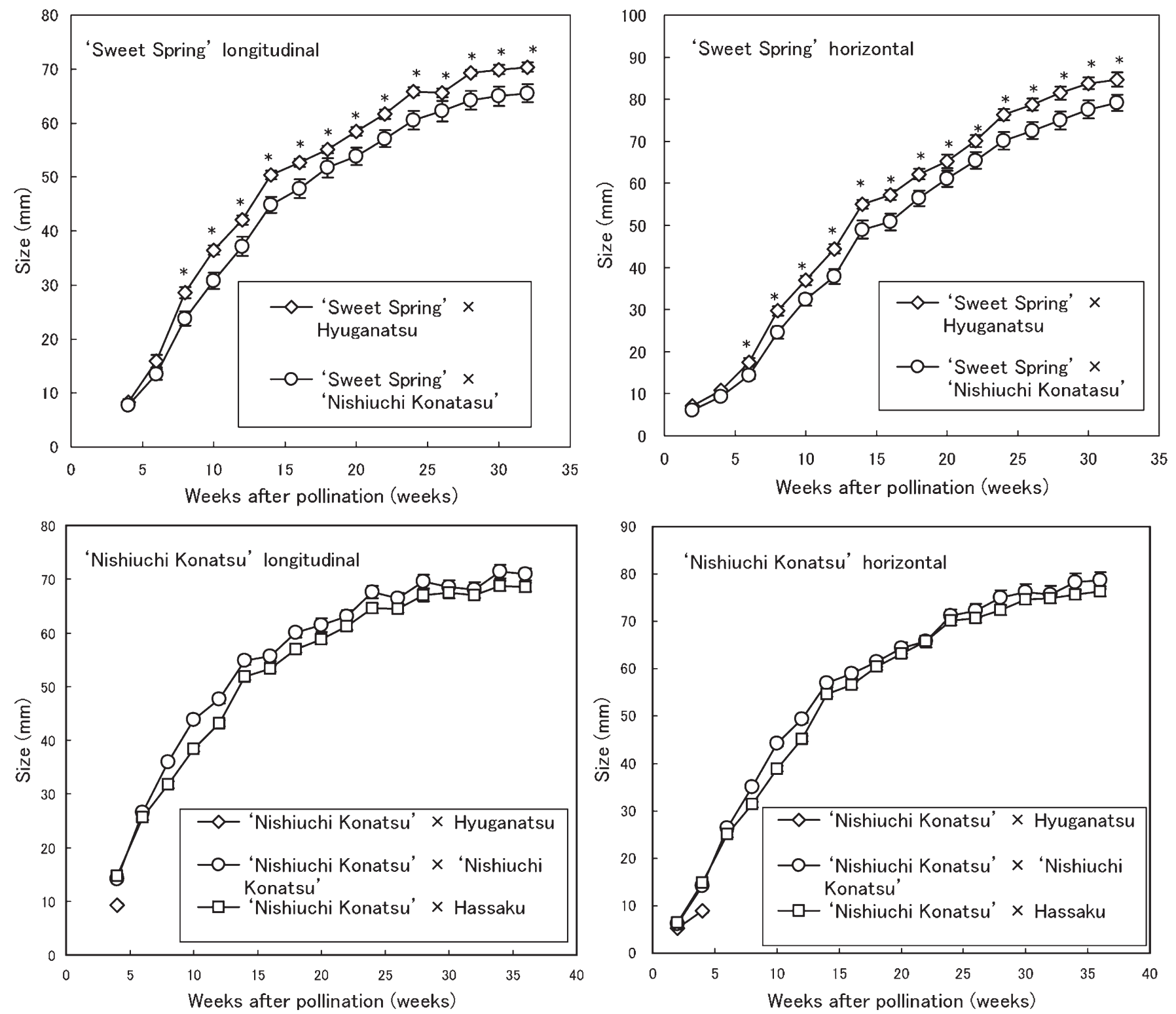

Fig. 2. Longitudinal and horizontal fruit development of 'Sweet Spring' and 'Nishiuchi Konatsu'. Symbols represent pollen source: Hyuganatsu $(\diamond)$, 'Nishiuchi Konatsu' $(\bigcirc)$, and Hassaku $(\square)$. Asterisks next to the symbols indicate significant differences among pollen sources. The bar on the symbol represents the SE

Table 2. Characteristics of the fruits obtained by pollination experiment in this study.

\begin{tabular}{|c|c|c|c|c|c|c|c|c|c|c|}
\hline \multirow[b]{3}{*}{ Seed parent } & \multirow[b]{3}{*}{ Pollen source } & \multirow{3}{*}{$\begin{array}{c}\text { No. of fruits } \\
\text { obtained }\end{array}$} & \multirow{2}{*}{\multicolumn{2}{|c|}{ Diameter $(\mathrm{mm})$}} & \multirow{3}{*}{$\begin{array}{l}\text { Fruit } \\
\text { wt (g) }\end{array}$} & \multirow{3}{*}{$\begin{array}{c}\text { Titratable } \\
\text { acidity ( } \% \text { as citric } \\
\text { acid content })\end{array}$} & \multirow{3}{*}{$\begin{array}{c}\text { TSS } \\
\text { content } \\
\text { (Brix \%) }\end{array}$} & \multirow{3}{*}{$\begin{array}{l}\text { Total } \\
\text { seed } \\
\text { wt }(\mathrm{g})\end{array}$} & \multicolumn{2}{|c|}{ No. of seeds } \\
\hline & & & & & & & & & $\overline{\text { Normal }}$ & Aborted \\
\hline & & & Longitudinal & Horizontal & & & & & seeds & seeds \\
\hline \multirow[t]{2}{*}{ Hyuganatsu } & 'Nishiuchi Konatsu' & $13(21.7)^{z}$ & 66.4 & 71.5 & 158.5 & 1.7 & 10.7 & 0.3 & 0.5 & 17.7 \\
\hline & & & NS & NS & NS & $* *$ & NS & $* *$ & $* *$ & ** \\
\hline \multirow{2}{*}{$\begin{array}{l}\text { 'Nishiuchi } \\
\text { Konatsu' }\end{array}$} & 'Nishiuchi Konatsu' & $29(48.3)$ & 69.5 & 76.9 & 178.9 & 1.0 & 8.2 & 0.6 & 1.2 & 23.8 \\
\hline & Hassaku & $27(45.0)$ & 70.1 & 77.4 & 188.5 & 1.1 & 8.9 & 7.5 & 27.9 & 3.7 \\
\hline \multirow[t]{3}{*}{ Hassaku } & 'Nishiuchi Konatsu' & $7(11.7)$ & 88.1 & 110.0 & 521.7 & 1.7 & 9.1 & 6.6 & 19.0 & 36.3 \\
\hline & Hyuganatsu & $8(13.3)$ & 90.3 & 112.2 & 534.0 & 1.8 & 9.2 & 15.5 & 48.6 & 2.8 \\
\hline & & & NS & NS & NS & NS & NS & $* *$ & $* *$ & ** \\
\hline \multirow[t]{3}{*}{ 'Sweet Spring' } & 'Nishiuchi Konatsu' & $17(56.7)$ & 65.6 & 78.4 & 218.4 & 0.8 & 8.8 & 1.9 & 11.7 & 3.2 \\
\hline & Hyuganatsu & $16(53.3)$ & 69.4 & 82.9 & 257.4 & 0.7 & 9.5 & 3.1 & 15.9 & 1.8 \\
\hline & & & $*$ & $*$ & $*$ & $*$ & $*$ & $* *$ & $* *$ & $*$ \\
\hline
\end{tabular}

${ }^{2}$ Number in parenthesis indicates fruit set ratio (\%).

y Number of fruit is a total of 2007 and 2008 seasons. Thus, fruit set was not calculated.

${ }^{x}$ Data were not obtained because of no fruit set.

NS, $*$ and $* *=$ Nonsignificant and significant difference at $5 \%$ and $1 \%$ level by $t$ test, respectively.

TSS $=$ total soluble solids. 

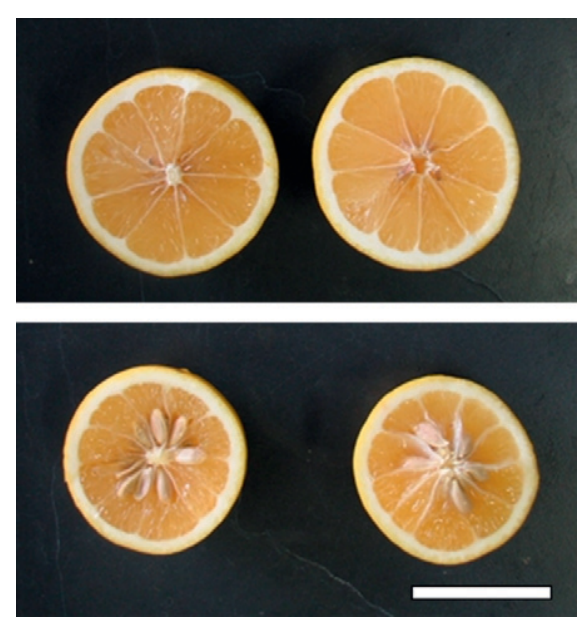

Fig. 3. Transverse sections of Hyuganatsu $\times$ 'Nishiuchi Konatsu' (upper) and Hyuganatsu $x$ Hassaku fruit (lower). The bar indicates $5 \mathrm{~cm}$.
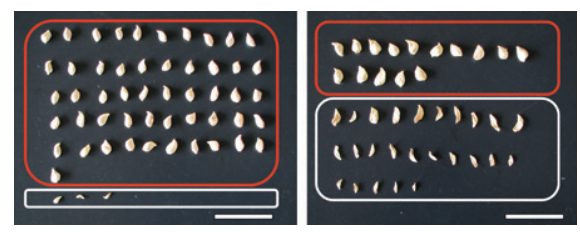

Fig. 4. Seeds obtained from Hassaku $\times$ Hyuganatsu (left) and Hassaku $\times$ 'Nishiuchi Konatsu' (right). Red and white lines enclose normal seeds and aborted seeds, respectively. The bars indicate $5 \mathrm{~cm}$.

whereas the fruits pollinated with 'Nishiuchi Konatsu' pollen were heterogeneous. A $\chi^{2}$ test to obtain the best fit ratio of seeds for Hassaku fruits demonstrated that none of the fruits obtained using Hyuganatsu pollen fit the ratios used in the test (Table 3). Fruits obtained using 'Nishiuchi Konatsu' pollen fit either $1: 1$ or $1: 2$, with one exception that did not match any of ratios tested in this study.

Finally, the fruitfulness and frequency of seed types appearing in this study are summarized in Table 4.

\section{Discussion}

Self-compatibility in 'Nishiuchi Konatsu'. Hyuganatsu cannot produce fruits by selfpollination as a result of its self-incompatible nature (Miwa, 1951). On the other hand, 'Nishiuchi Konatsu', a bud mutation of Hyuganatsu, can produce fruits by self-pollination, indicating that 'Nishiuchi Konatsu' is selfcompatible. Crosspollination between of Hyuganatsu $\times$ 'Nishiuchi Konatsu' set fruits but the reciprocal cross did not. Tanioka et al. (2001) noted the patrilineal compatibility of 'Nishiuchi Konatsu' the first time. The results of this study are in accordance with this previous report.

Many plants have a genetically determined self-incompatibility system in which the rejection of self-pollen grains is controlled by the alleles of an $S$ locus. Although the mechanism of self-incompatibility varies among species, a common feature of these $S$

Table 3. Number of normal and aborted seed in individual Hassaku fruits and results of $\chi^{2}$ test using several expected ratios.

\begin{tabular}{|c|c|c|c|c|c|c|c|}
\hline \multirow[b]{2}{*}{ Pollen source } & \multirow[b]{2}{*}{ No. } & \multirow{2}{*}{$\begin{array}{c}\text { Normal } \\
\text { seed }\end{array}$} & \multirow{2}{*}{$\begin{array}{c}\text { Aborted } \\
\text { seed }\end{array}$} & \multirow[b]{2}{*}{$\mathrm{df}$} & \multicolumn{3}{|c|}{$\chi^{2}$ value (probability) } \\
\hline & & & & & $2: 1^{z}$ & $1: 1$ & $1: 2$ \\
\hline \multirow{8}{*}{ Hyuganatsu } & 1 & 51 & 3 & 1 & $18.8(0.00)$ & $42.7(0.00)$ & $90.8(0.00)$ \\
\hline & 2 & 42 & 1 & 1 & $18.6(0.00)$ & $39.1(0.00)$ & $80.1(0.00)$ \\
\hline & 3 & 52 & 3 & 1 & $19.2(0.00)$ & $43.7(0.00)$ & $92.7(0.00)$ \\
\hline & 4 & 65 & 3 & 1 & $25.6(0.00)$ & $56.5(0.00)$ & $118.6(0.00)$ \\
\hline & 5 & 56 & 6 & 1 & $15.6(0.00)$ & $40.3(0.00)$ & $90.6(0.00)$ \\
\hline & 6 & 31 & 2 & 1 & $11.0(0.00)$ & $25.5(0.00)$ & $54.5(0.00)$ \\
\hline & 7 & 47 & 4 & 1 & $14.9(0.00)$ & $36.3(0.00)$ & $79.4(0.00)$ \\
\hline & 8 & 45 & 0 & 1 & $22.5(0.00)$ & $45.0(0.00)$ & $90.0(0.00)$ \\
\hline Sum of $\chi^{2}$ value & & & & 8 & $146.3(0.00)$ & $329.0(0.00)$ & $696.8(0.00)$ \\
\hline Whole individuals & & 389 & 22 & 1 & $144.8(0.00)$ & $327.7(0.00)$ & $695.3(0.00)$ \\
\hline Homogeneity & & & & 7 & $1.5(0.98)$ & $1.3(0.99)$ & $1.5(0.98)$ \\
\hline \multirow[t]{7}{*}{ 'Nishiuchi Konatsu' } & 1 & 32 & 38 & 1 & $13.8(0.00)$ & $0.5(0.47)$ & $4.8(0.03)$ \\
\hline & 2 & 35 & 37 & 1 & $10.6(0.00)$ & $0.1(0.81)$ & $7.6(0.01)$ \\
\hline & 3 & 15 & 25 & 1 & $15.3(0.00)$ & $2.5(0.11)$ & $0.3(0.58)$ \\
\hline & 4 & 13 & 33 & 1 & $30.5(0.00)$ & $8.7(0.00)$ & $0.5(0.47)$ \\
\hline & 5 & 14 & 42 & 1 & $43.8(0.00)$ & $14.0(0.00)$ & $1.8(0.19)$ \\
\hline & 6 & 3 & 39 & 1 & $67.0(0.00)$ & $30.9(0.00)$ & $13.0(0.00)$ \\
\hline & 7 & 21 & 40 & 1 & $28.5(0.00)$ & $5.9(0.01)$ & $0.0(0.86)$ \\
\hline Sum of $\chi^{2}$ value & & & & 7 & $209.5(0.00)$ & $62.5(0.00)$ & $28.0(0.00)$ \\
\hline Whole individuals & & 133 & 254 & 1 & $181.7(0.00)$ & $37.8(0.00)$ & $0.2(0.67)$ \\
\hline Homogeneity & & & & 6 & $27.8(0.00)$ & $24.7(0.00)$ & $27.8(0.00)$ \\
\hline
\end{tabular}

${ }^{2}$ Expected ratio to be used in $\chi^{2}$ test.

Table 4. Summary of fruit sets and seed types of the combinations of pollination in this study.

\begin{tabular}{llcl}
\hline Seed parent & \multicolumn{1}{c}{ Pollen source } & Fruit set & \multicolumn{2}{c}{ Frequent seed type } \\
\hline Hyuganatsu & 'Nishiuchi Konatsu' & Yes & Aborted seed \\
& Hassaku & Yes & Normal seed \\
'Nishiuchi Konatsu' & Hyuganatsu & Noz & \\
& 'Nishiuchi Konatsu' & Yes & Aborted seed \\
& Hassaku & Yes & Normal seed \\
Hassaku & Hyuganatsu & No & \\
& 'Nishiuchi Konatsu' & Yes & Normal and aborted seeds, but \\
& & & proportion varies among individual fruits \\
& Hyuganatsu & Yes & Normal seed \\
'Sweet Spring' & 'Nishiuchi Konatsu' & Yes & Mostly normal seeds, some aborted seeds exist \\
& Hyuganatsu & Yes & Normal seed \\
\hline
\end{tabular}

${ }^{\mathrm{z}}$ Obtained from Miwa (1951).

loci is that separate but tightly linked pollenand style-expressed genes (pollen $S$ and style $S$, respectively) determine the $S$ allele identity (Newbigin et al., 2008; Takayama and Isogai, 2005). The incompatibility system of citrus plant is supposedly of the gametophytic type (Ollitrault et al., 2007). If the self-incompatibility of Hyuganatsu is governed by the interaction between the products of pollen- and style-expressed $S$ genes like in other genera, the results of this study imply that the pollen-expressed gene(s) associated with self-incompatibility has mutated in 'Nishiuchi Konatsu'. In addition to Hyuganatsu, it is reported that Hassaku (Yamashita, 1980); pummelo (Citrus grandis L. Osbeck) (Soost, 1964); and some mandarins such as 'Imperial', 'Ellendale', 'Fortune', 'Edit', and 'Clementine' (Vardi et al., 2000; Wallace and Lee, 1999) are self-incompatible. Incompatible $S$ alleles are distributed widely, not only in self-incompatible accessions, but also in selfcompatible ones such as Satsuma mandarin, grapefruit, and 'Dancy' tangerine (Ollitrault et al., 2007), making self-incompatibility a hidden risk for a citrus breeding program. Therefore, a better understanding of the mechanism is essential for $S$ allele genotyping. However, at present, little information is available on the $S$ genotype in the genus Citrus. Soost $(1965,1968)$ proposed $S$ genotypes in some accessions. Kim et al. (2008) recently obtained Hyuganatsu-selfed progenies by bud pollination and they inferred that the $S$ genotype of Hyuganatsu is heterozygous ( $\mathrm{SaSb}$ ) from the number of pollen tubes in the style in the backcrossing of or crossing between selfed progenies. As information on the self-incompatibility in Hyuganatsu continues to be accumulated, 'Nishiuchi Konatsu' could be a good candidate for clarifying the genetic mechanism of self-incompatibility in the genus Citrus.

Seedlessness and reduction of seed number induced by 'Nishiuchi Konatsu' pollen. Because 'Nishiuchi Konatsu' pollinated with Hassaku pollen resulted in many normal seeds, 'Nishiuchi Konatsu' is at least female-fertile. Kitajima et al. (2001) reported that the number of normal seeds in the fruits of 'Nishiuchi Konatsu' and Hyuganatsu, which were pollinated with 'Suisho-Buntan' pollen, was not different 12 weeks after pollination, supporting the female fertility of 'Nishiuchi Konatsu'. When 'Nishiuchi Konatsu' was pollinated with Hassaku or 'Sweet Spring', which are not parthenocarpic, several normal seeds were developed. When 'Tosa-Buntan' 
was crossed with 'Nishiuchi Konatsu', more seeds were observed in the fruits than in fruits pollinated with Hyuganatsu pollen (Kitajima et al., 2001), suggesting that the pollen released from 'Nishiuchi Konatsu' is also functional. Therefore, the male or female sterility of 'Nishiuchi Konatsu' does not account for the seed abortion observed in this study; rather, a specific combination of a certain seed parent and 'Nishiuchi Konatsu' pollen is the cause. It may be concluded that seed abortion is the result of abnormalities in seed development triggered by pollination by 'Nishiuchi Konatsu' pollen.

In all citrus accessions used in this study, the fruits set by 'Nishiuchi Konatsu' pollen produced more aborted seeds than the ones pollinated by other controlled pollens. This is another characteristic feature of 'Nishiuchi Konatsu' pollen in addition to self-compatibility. It is especially interesting that not all of the seeds were aborted in Hassaku and 'Sweet Spring' fruits, unlike those obtained when Hyuganatsu and 'Nishiuchi Konatsu' were used as the seed parent and proportion of aborted seed differed among them. Moreover, in Hassaku, the number of aborted seeds varied among individual fruits. The proportion of aborted seeds to the total number of seeds was 0.51 to 0.92 when crossed with 'Nishiuchi Konatsu' pollen, but was 0.05 when crossed with Hyuganatsu pollen. This is a special feature expressed in the combination of Hassaku $\times$ 'Nishiuchi Konatsu' because there is no dispersion of the number of seeds regardless of seed parents and types in the others. The homogeneity among individual fruits of Hassaku $\times$ 'Nishiuchi Konatsu' was rejected by the $\chi^{2}$ homogeneity test. However, because all trees of Hassaku and 'Nishiuchi Konatsu' used in this study were clones, the variation of seed contents among individuals was not a result of the different genetic background. Thus, a strong male and female genotype effect was suggested. Moreover, a simple Mendelian segregation of gene associated seed formation was also rejected by the nonconvergent ratio of normal and aborted seeds as shown by the results of $\chi^{2}$ tests. Variability ratio in the cross between Hassaku and 'Nishiuchi Konatsu' may reflect an intermediary male and female interaction. In addition, a complex genetic segregation should be considered.

In the seedless cultivar Mukaku Kishu (C. kinokuni hort. ex Tanaka), arrested seed development at an early stage was reported as the cause of seedlessness (Yamasaki et al., 2007). Yamasaki et al. (2009) stated that arrested seeds were formed by gene expression in maternal tissues rather than in embryos. Because our present results show that aborted seeds appeared only in the 'Nishiuchi Konatsu'-pollinated fruits, seed abortion originates in either the embryo or endosperm, which are made from double fertilization, unlike 'Mukaku Kishu'. Ogata et al. (2008) obtained seedless 'Tosa-Buntan' fruits by pollination of the soft $\mathrm{x}$-ray-irradiated pollen. They reported that delayed degeneration of the embryo occurred in seedless fruits. Seedless fruits formed as a result of embryo degeneration can be categorized as stenospermocarpy. Thus, fertilization followed by the degeneration of the embryo in the fruits pollinated with 'Nishiuchi Konatsu' pollen is possibly expected.

Fruit characteristics. A linear relationship between fruit size and seed number is common in citrus varieties, indicating the strong influence of seeds on fruit development (Hearn et al., 1969). In the results of this study, however, all but 'Sweet Spring' showed no difference in fruit size regardless of the pollen source, although the number of seeds is affected. In 'Sweet Spring', the pollen source affected fruit development and characteristics in addition to the number of seeds. This metaxenia-like effect has been reported in several citrus varieties such as 'Ellendale' (Vithanage, 1991) and 'Ellenor' (Wallace and Lee, 1999).

\section{Conclusion}

Features regarding compatibility and seed type in each pollination combination are summarized in Table 4. In this study, the unique characteristics of the compatibility and seed formation of 'Nishiuchi Konatsu' have been demonstrated. 'Nishiuchi Konatsu' showed the self-compatibility as well as the compatibility to Hyuganatsu, which is an original strain of 'Nishiuchi Konatsu'. In addition, the numbers of seeds in the fruits obtained by these combinations dramatically decreased compared with those pollinated with the pollens from other citrus strains. Another interesting feature of 'Nishiuchi Konatsu' is that the fruits obtained by Hassaku $x$ 'Nishiuchi Konatsu' reduced the number of seeds compared with other pollen sources. However, not all of the seeds disappeared and the ratio of normal and aborted seeds varied among individual fruits. In conclusion, 'Nishiuchi Konatsu' is not only a good candidate to elucidate the mechanism of selfincompatibility and seed abortion in citrus plants, but also useful as a breeding material to introduce these characteristics.

\section{Literature Cited}

Hearn, C.J., P.C. Reece, and R. Fenton. 1969. Selfincompatibility and the effects of different pollen sources upon fruit characteristics of four Citrus hybrids. Proc. First Intl. Citrus Sym. 1:183-187.

Imai, A., T. Takahara, N. Hiehata, H. Fukamachi, R. Matsumoto, T. Yoshioka, and T. Kuniga. 2007. The new pollinizer cultivar 'Kankitsu Kuchinotsu 41 Gou' for few-seeded fruit production of hyuga-natsu (Citrus tamurana hort. ex Tanaka). Hort. Res. (Japan) 6(suppl. 1):39. [in Japanese].

Kim, J.H., A. Wakana, and K. Sakai. 2008. Production of homozygous 'Hyuganatsu' S1 seedlings for $\mathrm{S}$ alleles and their cross incompatibility. Hort. Res. (Japan) 7(suppl. 2):109 [in Japanese].

Kitajima, A., Y. Okada, and K. Hasegawa. 2001. Pollen tube growth, fertilization and seed development in Hyuganatsu (Citrus tamurana) seedless cultivars 'Muroto-Konatsu' and 'NishiuchiKonatsu'. J. Jpn. Soc. Hort. Sci. 70:320-327. [in Japanese with English summary].

Miwa, T. 1951. Pollination, fertilization and fruit drop in Citrus tamurana HORT. Miyazaki
Univ. Bull. 2:1-67. [in Japanese with English summary].

Newbigin, E., T. Paape, and J.R. Khon. 2008. RNase-based self-incompatibility: Puzzled by pollen S. Plant Cell 20:2286-2292.

Ogata, T., T. Takeichi, K. Matsunaga, K. Hasegawa, S. Yamane, and K. Sugiyama. 2008. Seed abortion of 'Tosa-Buntan' pummelo pollinated with soft-X-irradiated pollens. Sci. Hort. 116: 180-185.

Ollitrault, P., F. Luro, and M. Yamamoto. 2007. Seedlessness and ploidy manipulations, p. 197218. In: Khan, I. (ed.). Citrus genetics, breeding and biotechnology. CAB International, Oxfordshire, UK

Soost, R.K. 1964. Self-incompatibility in Citrus grandis (Linn.). Osbeck. Proc. Amer. Soc. Hort. Sci. 84:137-140.

Soost, R.K. 1965. Incompatibility alleles in the genus Citrus. Proc. Amer. Soc. Hort. Sci. 87:176-180.

Soost, R.K. 1968. The incompatibility gene system in citrus. Proc. First Intl. Citrus Sym. 1:189-190.

Takayama, S. and A. Isogai. 2005. Selfincompatibility in plants. Annu. Rev. Plant Biol. 56:467-489.

Tanioka, H., M. Tanaka, T. Aoki, and S. Iroi. 2001. The characteristics of Hyuganatsu (C. tamurana Hort. ex Tanaka) cultivars 'Sukumokonatsu' and 'Nishiuchikonatsu' in protected cultivation. Bull. Kochi Agr. Res. Cent. 10:99-106. [in Japanese with English summary].

Vardi, A., H. Neumann, A. Frydman-Shani, Y. Yaniv, and P. Spiegel-Roy. 2000. Tentative model on the inheritance of juvenility, selfincompatibility and parthenocarpy. Acta Hort. 535:199-205.

Vithanage, V. 1991. Effect of different pollen parents on seediness and quality of 'Ellendale' tangor. Sci. Hort. 48:253-260.

Wallace, H.M. and L.S. Lee. 1999. Pollen source, fruit set and xenia in mandarins. J. Hort. Sci. Biotechnol. 74:82-86.

Yamamoto, M., R. Matsumoto, and Y. Yamada. 1995. Relationship between sterility and seedlessness in Citrus. J. Jpn. Soc. Hort. Sci. 64:23-29.

Yamamoto, S. and N. Iwasaki. 1994. Production of seedless fruits of Hyuganatsu (Citrus tamurana hort. ex Tanaka) in plastic house. Abstracts XXIVth International Horticultural Congress. 246.

Yamasaki, A., A. Kitajima, N. Ohara, M. Tanaka, and K. Hasegawa. 2007. Histological study of expression of seedlessness in Citrus kinokuni 'Mukaku Kishu' and its progenies. J. Amer. Soc. Hort. Sci. 132:869-875.

Yamasaki, A., A. Kitajima, N. Ohara, M. Tanaka, and K. Hasegawa. 2009. Characteristics of arrested seeds in Mukaku Kishu-type seedless Citrus. J. Jpn. Soc. Hort. Sci. 78:61-67.

Yamashita, K. 1976. Production of seedless fruits in Hyuganatsu, Citrus tamurana Hort. ex TANAKA, and Hassaku, Citrus hassaku HAYATA through pollination with pollen grains from the 4x Natsudaidai, Citrus natsudaidai HAYATA. J. Jpn. Soc. Hort. Sci. 45:225-230.

Yamashita, K. 1980. Studies on self-incompatibility of Hassaku (Citrus hassaku hort. ex Tanaka) I. On the pollen behavior in pistils in self-pollination, and the effect of various treatments to overcome the self-incompatibility. J. Jpn. Soc. Hort. Sci. 49:49-56

Yamashita, K., K. Oda, and N. Nakamura. 1990. Seed development in self-pollination of $4 \mathrm{X}$ Hyuganatsu and reciprocal crosses between $2 \mathrm{X}$ and $4 \mathrm{X}$ Hyuganatsu, and overcoming the self-incompatibility of $2 \mathrm{X}$ Hyuganatsu using pollen of 4X Hyuganatsu. J. Jpn. Soc. Hort. Sci. 59:23-28. 